\title{
Exploring the effect of COVID-19 on airline environmental efficiency through an interval epsilon-based measure model
}

\author{
Ye $\mathrm{Li}^{1} \cdot$ Xing-chun Huang ${ }^{1} \cdot$ Qiang $\mathrm{Cui}^{2} \mathbb{C}$
}

Received: 27 August 2021 / Accepted: 14 November 2021 / Published online: 30 November 2021

(c) The Author(s), under exclusive licence to Springer-Verlag GmbH Germany, part of Springer Nature 2021

\begin{abstract}
COVID-19 has dealt an unprecedented blow to the aviation industry since 2020. This paper applies the interval epsilonbased measure (IEBM) model to evaluate the optimal quarterly environmental efficiency of 14 global airlines of passenger and cargo subsystems during 2018-2020. Then, the time series prediction method is applied to forecast the interval data of inputs and outputs from 2021 to 2022. Finally, we can calculate the quarterly efficiency. Thus, the future development trends of airlines can be predicted. The results show that (1) COVID-19 has hit the passenger subsystem harder, while the freight subsystem has become more efficient; (2) the efficiency of the freight subsystem has inevitably declined in the post-epidemic era; and (3) therefore, the airlines will have a " $\sqrt{ }$ " shaped recovery curve in the next few years.
\end{abstract}

Keywords Airline environmental efficiency · Parallel system · Interval epsilon-based measure model · Time series prediction

\section{Introduction}

From late 2019 to early 2020, the COVID-19 epidemic swept the world with sudden momentum. Many industries suspended commercial transactions to prevent the virus from spreading widely. Aviation is one of the most affected industries. The border closures, flight cancellations, and aircraft grounding led to a sharp drop in airline revenue. According to the latest International Civil Aviation Organization (ICAO) report, the total number of passengers decreased by 2,699 million $(-60 \%)$, and the entire passenger revenue lost $\$ 371$ billion around the world in 2020 (ICAO 2021). In terms of changes in the impact on the environment, with the cancellation of flights, carbon dioxide emissions have decreased. According to the ICAO, the carbon emission baseline for "Carbon Neutral Growth from 2020 strategy" (CNG2020 Strategy) has been adjusted, which directly

Responsible Editor: Eyup Dogan

Qiang Cui

cuiqiang@seu.edu.cn

1 School of Business Administration, Nanjing University of Finance and Economics, Nanjing 210023, China

2 School of Economics and Management, Southeast University, Nanjing 211189, China influences the environmental efficiency of airlines. Unlike the short V-shaped recovery curve during the SARS epidemic in 2003, the recovery curve of airlines in the postCOVID-19 era is more complex and changeable. In this context, it is of significant meaning to study the future development of global airlines.

Carbon emission has become a global economic and social issue. With the rapid development of aviation industry, aviation carbon emissions increased by about $80 \%$ from 1990 to 2014 . In the next 20 years, the growth rate is expected to be about $45 \%$. The reduction of carbon dioxide emissions presents a dilemma for airlines nowadays, because carbon dioxide is the inevitable result of operational needs. With the increasing awareness of environmental protection, the energy-saving and emission-reduction targets of international organizations have put airlines under pressure. Improving the efficiency of carbon dioxide emissions is of great significance for airlines to meet these challenges. Some indicators, such as the carbon dioxide emission index (CEI), carbon dioxide emission intensity (Sun 2005), and per capita carbon dioxide emissions (Tol et al. 2009), can only reflect some aspects. It is more reasonable to combine all relevant indicators to get one overall index. Therefore, it is necessary to measure the environmental efficiency of airlines.

Passenger transportation accounts for a large proportion of modern airline services, while the proportion of freight 
transportation is slowly increasing, enabling the global trade supply chain to function normally (Givoni and Chen 2017). The COVID-19 has affected the two subsystems to varying degrees. The border blockade has restricted people's freedom of movement and made a disastrous impact on passenger transportation. At the same time, the freight system needs to undertake fast, accurate, and scalable transportation requirements. The quantity of cargo transportation in some airlines will even increase in 2020 . Therefore, the airlines cannot ignore the importance of the freight system during the COVID-19 outbreak. What about the future trend of the two subsystems? This paper discusses the allocation of shared resources between the two parallel subsystems and their different influence on the overall efficiency of airlines.

On the discussion method of efficiency, Cui and Li et al. (2018) used a neural network to predict the efficiency of 29 international airlines during 2021-2023. They then proposed a network epsilon-based measure with managerial disposability to discuss the differences. BP neural network has been widely used in airline input-output indication prediction because of its good performance in non-linear function approximation. However, the traditional neural network has disadvantages such as slow convergence speed, sample dependence, and local extreme value, resulting in an unstable prediction process. More importantly, the precise data predicted by the BP neural network may differ because of inaccurate numbers, such as interval values, bounded values, and fuzzy values. Therefore, the time series prediction theory on interval data is adopted to obtain the inputs and outputs of 14 airlines in each quarter from 2021 to 2022. Referring to Cui and Li et al. (2018), we can know that the epsilon-based measure (EBM) model proposed by Tone and Tsutsui (2010) can handle both radial and non-radial inputs and outputs and effectively improve the precise measurement. This paper presents an interval EBM model to evaluate sample airlines' quarterly overall and subsystem efficiency with the predicted interval values. Furthermore, based on the inefficient subsystem, practical methods are proposed.

Questions to be answered include (1) How to reasonably allocate the shared resources between passenger and freight subsystems? (2) How does time series theory reasonably predict the interval values of input and output indicators? and (3) How to use the interval EBM model to evaluate the quarterly environmental efficiency from 2021 to 2022 ?

The rest of this article is organized as follows. The "Literature review" section reviews the literature on airline efficiency evaluation and the latest articles about the impact of COVID-19 on airline efficiency. The "Methodology" section introduces the construction of the interval EBM model. The "Empirical study" section outlines the empirical process: data collection, practical design, and experimental operation. The experimental results and analysis are presented in the "Results and discussion" section. The last section is the conclusion and future research directions.

\section{Literature review}

A variety of methods had been applied to research airline efficiency, such as the TOPSIS method (Barros and Wanke 2015; Bae et al. 2021), factor analysis (Siregar and Norsworthy 2001; Barbot et al. 2008; Pappachan 2020); stochastic frontier analysis (SFA), and data envelopment analysis (DEA) method (Bhadra 2009; Ouellette et al. 2010; Tavassoli et al. 2021). The SFA and DEA models have advantages in calculating a single efficiency index with multiple inputs and outputs, which can be identified as a benchmark for decision-making units (DMUs). Compared with SFA, DEA is a non-parametric method and has more obvious advantages. It has no specific provisions on the functional form and can get rid of the influence of subjective factors. Therefore, the DEA models have been widely applied in recent papers.

The existing DEA models can be divided into two typesradial model and non-radial model. Scholars proposed the former earlier, such as Charnes-Cooper-Rhodes (CCR) and Banker-Charnes-Cooper (BCC) models (Hong and Zhang 2010; Wang et al. 2011; Min and Joo 2016; Adabavazeh and Nikbakht 2020), and then combined the standard DEA model with other methods such as the Malmquist productivity index and Fisher productivity index (Ray and Mukherjee 1996; Greer 2008; Merkert and Hensher 2011; Wu and Liao 2014; Pacagnella Junior et al. 2020). However, the nature of the radial model determines that it has many disadvantages. First, it assumes that inputs and outputs change in the same proportion while not precisely in practice. Secondly, the radial DEA model ignores the influence of non-radial slack on efficiency, that is, when the efficiency of an airline is one. Still, the slack is not 0 ; it cannot be determined whether the airline is fully effective or weakly effective, resulting in biased estimation results.

The non-radial model appears in response to the condition. In recent years, many non-radial models have been applied to airline efficiency evaluation, such as the slacksbased measure (SBM) model (Tone 2001) and rangeadjusted measure (RAM) model (Aida et al. 1998). Next came the expansion and deformation of the non-radial models. Cui et al. (2018) applied the virtual frontier SBM model to discuss the effect of carbon dioxide emissions on the efficiency of 22 airlines with strong and weak disposability. Heydari et al. (2020) proposed a fully fuzzy network RAM model for evaluating 14 Iranian airlines and extended the network RAM model under the fully fuzzy framework. Finally, introduced the two-stage adverse network slackbased measure (NSBM) method to explore the efficiency of 
the production stage and profit stage of 9 Chinese airlines. The results showed that airlines performed well in the economic benefit acquisition stage, and the low productivity conversion rate was the reason for the low overall efficiency.

However, the non-radial model is not perfect for any situation. When there is undesirable output in the model, the input and undesirable output are linked together, showing a radial relationship — while the input and the desired output tend towards separation, showing a non-radial relationship. The non-radial model cannot correctly deal with the two connections, resulting in the underrated efficiency. The epsilon-based measure (EBM) model can overcome the above defects, introducing exponents $\varepsilon$ to measure the diversity and interdependence between vectors. A small set of papers have applied the EBM model to evaluate the environmental efficiency of different industries. Tavana et al. (2013) proved the rationality of the network EBM model by taking the semiconductor industry as an example and considering its internal networking activities. Xu and Cui (2017) applied the network EBM model to evaluate the performance of 19 airlines and determined the influencing factors by regression analysis. Cui and Li et al. (2018) proposed a NEBM model with managerial disposability to measure the influence of the CNG2020 strategy on multi-function airlines during the pilot phase (2021-2023). Wu et al. (2019) applied the EBM evaluation model on the productive efficiency of a large coal enterprise in China from 2015 to 2017 for the future of coal energy. Cui and Arjomandi (2021) modified the rangeadjusted measure (RAM) model with an epsilon-based measure model and enriched the theoretical framework of airline performance appraisal. Wang et al. (2021) applied the Malmquist index and EBM model to 14 port companies in Vietnam to prove the validity and fairness of this hybrid model. By far, the EBM model has not been widely applied in the efficiency evaluation of the aviation industry. This paper used the EBM model combining the interval DEA model to study the efficiency of airlines.

The traditional DEA model assumes that input and output data are accurate, but not the case. Scholars have long studied how to evaluate the efficiency and put forward the interval DEA model (IDEA). Cooper et al. (1999) proposed an IDEA model with assurance region (AR). The boundaries were based on variables rather than data, which involved inaccurate data and the concept of cone-ratio envelopment. Lee et al. (2002) applied an additional DEA model to identify specific DMU inefficiencies in slack, peer groups, and returns to scale. Wang et al. (2005) constructed a pair of new interval DEA models for measuring the lower bound and upper bound of the optimal relative efficiency and introduced a minimax regret-based (MRA) approach to rank interval efficiency. Kuo (2011) proposed an effective method based on VIKOR, GRA, and interval-valued fuzzy sets to evaluate the service quality of cross-strait passenger airlines in China. Azizi and Wang (2013) proposed a pair of improved bounded DEA models to measure each country's performance in the 2004 Summer Olympic Games in Athens, overcoming the shortcomings of the traditional model that could not determine the interval efficiency. An et al. (2018) combined DEA and analytic hierarchy process (AHP) to complete the ranking of decision-making units based on interval cross efficiency. Zhou et al. (2019) constructed a dynamic three-stage network DEA model considering decision-makers' optimistic and pessimistic attitudes to evaluate the sustainable supply chain (SSC). Arana-Jiménez et al. (2021) developed a two-stage SBM model to assess the efficiency when the data were integer and interval values. Based on the BCC model and simple Russell model, Poordavoodi et al. (2020) combined the interval DEA model with interval entropy weight to evaluate the efficiency of Web services. Cheng et al. (2020) proposed a three-stage IDEA model to measure the efficiency of interval data and eliminate the influence of external environmental factors. Cui et al. (2020) applied the interval SBM model to measure the impact of Carbon Neutral Growth from the 2020 (CNG2020) strategy on the efficiency of 24 airlines during the period 2021-2022. Davoudabadi et al. (2021) combined DEA and fuzzy simulation of interval-valued intuitionistic fuzzy sets (IVIFSs) to evaluate the efficiency of renewable energy projects. The above traditional interval efficiency studies were primarily based on SBM and RAM models, and few studies applied EBM models. Therefore, this paper innovatively proposes the interval EBM (IEBM) model.

Before this, each airline was considered a whole with multiple inputs and outputs, and the "black box" had not yet been opened. Therefore, the experts began to propose a network DEA model to solve this problem. The network DEA model decomposes the decision-making unit into several subsystems and processes and judges their relationship through components and intermediates. Different subsystems may be in series, parallel, or a combination of both. This paper studies the parallel sectors of airlines-passenger and freight subsystems. Li and Cui et al. (2018) calculated the efficiency of 29 airlines from 2008 to 2015 by using the three-stage network RAM model with shared inputs and obtained the optimal employee allocation ratios. The results showed that most airlines' maximum number of employees should be allocated to the sales phase. It is clear that there are shared inputs and outputs between different stages, but few papers discuss shared undesirable outputs. Following the research direction of the above paper, this paper applies the IEBM model to solve this problem with undesirable output-greenhouse gas emissions.

This paper focuses on the impact of COVID-19, whose outbreak has dealt a heavy blow to the aviation industry. In particular, passenger traffic had a striking decline in the first half of 2020. Several airlines have filed for bankruptcy. By 
2021, things aren't much better. In addition to direct revenue decline, COVID-19 affects operation mode, harmful gas emissions, input-output indicators. Therefore, a comprehensive study should be conducted on the changes in airline environmental performance. Suau-Sanchez et al. (2020) found that the epidemic significantly reduced the industrial scale, with full-service airlines bearing the brunt. Nižetić (2020) concluded that the epidemic had a significant impact on the revenues of the entire aviation industry, which was expected to recover next year. The primary response measures implemented by the airlines in Budd et al. (2020) were to change route operations, rationalize the fleet, reduce the number of employees, and reconfigure capacity. Czerny et al. (2021) also suggested increasing air cargo volume and giving play to the government's regulatory role. However, not much has been written about the role of air cargo. The International Air Transport Association (IATA) report showed that the cargo revenue of the international airline industry increased by $15 \%$ in 2020 from 2019 due to the coronavirus disease. Many airlines converted passenger planes to cargo ones to meet the demand for cargo transportation. What is the recovery curve for passenger and freight subsystems in the post-epidemic era? Therefore, this paper re-screens the input-output indicators, reconstructs the evaluation system, and predicts the response.

In this paper, an interval EBM model with strong disposability is proposed to evaluate the efficiency of 14 largescale airlines under the background of COVID-19. Based on the quarterly data of 14 global airlines from 2018 to 2020 , the grey theory is used to forecast the quarterly data during 2021-2022. Empirical results can provide decision-makers with practical measures.

\section{Methodology}

Airline environmental efficiency evaluation is one of the most potential applications with DEA models. The epsilonbased measure (EBM) model has a more vital ability to discriminate the efficient DUMs. The EBM model unifies radial and non-radial models in a composite framework by two parameters: a scalar and a vector. When solving these two values, the affinity index was introduced to replace the Pearson correlation coefficient. Slacks of the EBM model can provide information about inefficient DUMs so that decision-makers can remedy the case.

Suppose there are $k$ decision-making units to be evaluated. Each DMU includes $m$ inputs to produce $n$ desirable outputs and $l$ undesirable outputs. Traditional DEA models only focusing on the hot production index may be unreasonable. This paper treats the undesirable output with strong disposability since Cui et al. (2018) indicated that the strong disposability is more reasonable when dealing with the undesirable outputs than the weak disposability.

Then, the input-oriented network EBM model is defined as follows:

$$
\begin{gathered}
\gamma^{*}=\min \sum_{k=1}^{K}\left(\theta_{k}-\varepsilon_{x}^{k} \sum_{i=1}^{m_{k}} \frac{w_{i}^{k-} s_{i}^{k-}}{x_{i 0}^{k}}\right) \\
\text { s.t. } \theta_{k} X_{i 0}^{k}=\lambda^{k} X^{k}+s^{k-}, \mathrm{i}=1, \cdots, \mathrm{M} \\
Y_{p 0}^{k} \leq \lambda^{k} Y^{k}, \mathrm{p}=1, \cdots, \mathrm{N} \\
\theta_{k} Z_{q 0}^{k}=\lambda^{k} Z^{k}+s^{k-}, \mathrm{q}=1, \cdots, \mathrm{L} \\
\lambda^{k} \geq 0 \\
s^{k-} \geq 0
\end{gathered}
$$

In model (1), each of the DUMs can be subdivided into $k$ subsystems. $x_{i}^{k}, y_{p}^{k}$ denote the $i$ th input and the $p$ th desirable output of $D M U_{k}, z_{q k}$ denotes the $q$ th undesirable output of $D M U_{k}, k=1,2, \cdots, K$. The undesirable output is treated as input in the same way as they are handled. $s_{i}^{-}$stands for the slacks of the $i$ th input. $\varepsilon_{x}^{k}$ is the core parameter combining radial $\theta_{k}$ and non-radial slacks. $w_{i}^{k-}$ is the relative importance of the input, which should be a unit-constant value in the input-oriented model (1).

In addition to input-oriented, there are also output-oriented and no-oriented network models:

$$
\begin{gathered}
\gamma^{*}=\min \frac{1}{\left(\sum_{k=1}^{K}\left(\theta_{k}+\varepsilon_{y}^{k} \sum_{p=1}^{n_{k}} \frac{w_{p}^{k+k} s_{p}^{k+}}{y_{p 0}^{k}}\right)\right)} \\
\text { s.t. } \theta_{k} X_{i 0}^{k} \geq \lambda^{k} X^{k}, \mathrm{i}=1, \cdots, \mathrm{M} \\
Y_{p 0}^{k}=\lambda^{k} Y^{k}-s^{k+}, \mathrm{p}=1, \cdots, \mathrm{N} \\
\theta_{k} Z_{q 0}^{k} \geq \lambda^{k} Z^{k}, \mathrm{q}=1, \cdots, \mathrm{L} \\
\lambda^{k} \geq 0 \\
s^{k+} \geq 0
\end{gathered}
$$

$$
\begin{aligned}
& \gamma^{*}=\min \sum_{k=1}^{K}\left(\frac{\theta_{k}-\varepsilon_{x}^{k} \sum_{i=1}^{m_{k}} \frac{k_{i}^{k-k} s_{i}^{k-}}{\lambda_{i 0}^{k}}}{\eta_{k}+\varepsilon_{y}^{k} \sum_{p=1}^{n_{k}} \frac{k_{p}^{k}+p_{p+}^{k+}}{y_{p 0}^{k}}}\right) \\
& \text { s.t. } \theta_{k} X_{i 0}^{k} \geq \lambda^{k} X^{k}, \mathrm{i}=1, \cdots, \mathrm{M} \\
& Y_{p 0}^{k} \leq \lambda^{k} Y^{k}, \mathrm{p}=1, \cdots, \mathrm{N} \\
& \theta_{k} Z_{q 0}^{k} \geq \lambda^{k} Z^{k}, \mathrm{q}=1, \cdots, \mathrm{L} \\
& \lambda^{k} \geq 0 \\
& s^{k-}, s^{k+} \geq 0
\end{aligned}
$$

This paper applies the input-oriented model for research. The EBM model with the interval DEA is combined based on the assumption that the data of input and output indicators are inaccurate. For $D U M_{0}$, the most unfavorable situation is that the desirable outputs are the smallest while the inputs and undesirable outputs are the largest. The minimum efficiency can be gotten as this time. The situation of the maximum efficiency is the opposite. The minimum efficiency of $D U M_{0}$ is defined as follows: 


$$
\begin{gathered}
\min \gamma^{*}=\min \sum_{k=1}^{K}\left(\theta_{k}-\varepsilon_{x}^{k} \sum_{i=1}^{m_{k}} \frac{w_{i}^{k-} s_{i}^{k-}}{x_{i 0}^{k}}\right) \\
- \\
\text { s.t. } \theta_{k} X_{i 0}^{k}=\lambda^{k} \overline{X^{k}}+s^{k-}, \mathrm{i}=1, \cdots, \mathrm{M} \\
\overline{-} \\
Y_{p 0}^{k} \leq \lambda^{k} Y^{k}, \mathrm{p}=1, \cdots, \mathrm{N} \\
\theta_{k} Z_{q 0}^{k}=\lambda^{k} \overline{Z^{k}}+s^{k-}, \mathrm{q}=1, \cdots, \mathrm{L} \\
-\quad \lambda^{k} \geq 0 \\
s^{k-} \geq 0
\end{gathered}
$$

For $D U M_{0}$, the most favorable situation is that the desirable outputs are the largest while the inputs and undesirable outputs are the smallest. Similarly, the maximum efficiency is:

$$
\begin{gathered}
\max \bar{\gamma} *=\min \sum_{k=1}^{K}\left(\theta_{k}-\varepsilon_{x}^{k} \sum_{i=1}^{m_{k}} \frac{w_{i}^{k-} s_{i}^{k-}}{\overline{x_{i 0}^{k}}}\right) \\
\text { s.t. } \theta_{k} \overline{X_{i 0}^{k}}=\lambda^{k} X^{k}+s^{k-}, \mathrm{i}=1, \cdots, \mathrm{M} \\
Y_{p 0}^{k} \leq \lambda^{k} \overline{\overline{Y^{k}}}, \mathrm{p}=1, \cdots, \mathrm{N} \\
\theta_{k} \overline{Z_{q 0}^{k}}=\lambda^{k} Z^{k}+s^{k-}, \mathrm{q}=1, \cdots, \mathrm{L} \\
-\lambda^{k} \geq 0 \\
s^{k-} \geq 0
\end{gathered}
$$

The interval efficiency of the subsystem $k$ should be:

$\left\{\underline{\gamma}^{*}=\sum_{k=1}^{K}\left(\theta_{k}-\varepsilon_{x}^{k} \sum_{i=1}^{m_{k}} \frac{w_{i}^{k-} s_{i}^{k-}}{x \underline{0^{k}}}\right), \bar{\gamma} *=\sum_{k=1}^{K}\left(\theta_{k}-\varepsilon_{x}^{k} \sum_{i=1}^{m_{k}} \frac{w_{i}^{k-} s_{i}^{k}}{x_{10}^{k}}\right)\right\}$

The key to applying interval EBM model is to determine the value of $\varepsilon_{x}$ and $w^{-}$. Referred to Tone and Tsutsui (2010), the two parameter values are calculated by the following steps:

Step 1: Introduce the "diversity index".

In the model, $\mathrm{a} \in R_{+}^{n}, \mathrm{~b} \in R_{+}^{n}$ are the specific observations for the inputs of $k$ DMUs. The diversity index represents the degree of dispersion between vectors $\mathrm{a}, \mathrm{b}$ and $\overline{c_{j}}$, and then can be written as:

$$
\begin{gathered}
c_{j}=\ln \frac{b_{j}}{\alpha_{j}} \\
\bar{c}_{j}=\sum_{j=1}^{m} \frac{c_{j}}{n} \\
c_{\min }=\min \left(\mathrm{c}_{j}\right) \\
c_{\max }=\max \left(\mathrm{c}_{j}\right) \\
D(\alpha, b)=\frac{\sum_{j=1}^{m}\left|\mathrm{c}_{j}-\overline{\mathrm{c}}_{j}\right|}{n\left(c_{\max }-c_{\min }\right)}
\end{gathered}
$$

Step 2: Introduce the "affinity index".
Different from the Pearson correlation coefficient greatly affected by outliers, the affinity index $\mathrm{S}(a, b)$ is defined to perform correlation analysis of vectors $a, b$ :

$\mathrm{S}(\alpha, b)=1-2 \mathrm{D}(\alpha, b)$

Because $0 \leq \mathrm{D}(a, b) \leq \frac{1}{2}$, then $0 \leq \mathrm{S}(a, b) \leq 1$.

Step 3: Calculate the values of parameter $\varepsilon_{x}$ and $w^{-}$:

$$
\begin{gathered}
\varepsilon_{x}=\frac{m-\rho_{x}}{m-1}(m>1) \\
\varepsilon_{x}=0(m=1) \\
w^{-}=\frac{w_{x}}{\sum_{i=1}^{m} w_{x i}}
\end{gathered}
$$

In the above model, $\rho_{x}$ is the biggest eigenvalue of $\mathrm{S}(a, b)$, and $w_{x i}$ is the corresponding vector of $\rho_{x}$.

\section{Empirical study}

Fourteen global airlines are set as the empirical research subjects after careful siftings. They are Aeroflot, Air China, All Nippon Airways, Cathay Pacific Airways, China Airlines, China Eastern Airlines, China Southern Airlines, Eva Air, Hainan Airlines, Juneyao Airlines, KLM Royal Dutch, Lufthansa Airlines, Singapore Airlines, and Spring Airlines. As a result, Lufthansa Airlines, China Eastern Airlines, China Southern Airlines, Air China, Singapore Airlines, and KLM Royal Dutch are among the top 20 airlines globally by passenger volume in 2020. In addition, sample airlines come from different countries and continents so that they can be certain representatives.

The selection of inputs and outputs makes a big difference. Based on the parallel structure of airlines, this paper needs to select the respective input and output indices and shared indices of the passenger and freight systems, available seat kilometer (ASK) reflects the maximum passenger economic benefits airlines can obtain from operating routes and capacity resources. Therefore, it is a crucial business indicator to determine the airline passenger subsystem's performance. When the air transportation market is stagnant, changes in the ASK are apparent. Revenue passenger kilometer (RPK) as a corresponding index reflects the number of passengers and profitability of air transportation. Likewise, available tonne kilometer (ATK) and revenue tonne kilometer (RTK) are selected as input and output unique to the freight system. There are shared resources between the passenger and freight systems in daily operations. Operating costs (OC) and operating revenue (OR) are direct and common shared indicators. Carbon dioxide emissions $\left(\mathrm{CO}_{2}\right)$ are selected as undesirable output, always dealt with five disposability approaches in Cui et al. (2020). The parallel structure of the airline is shown in Fig. 1. 


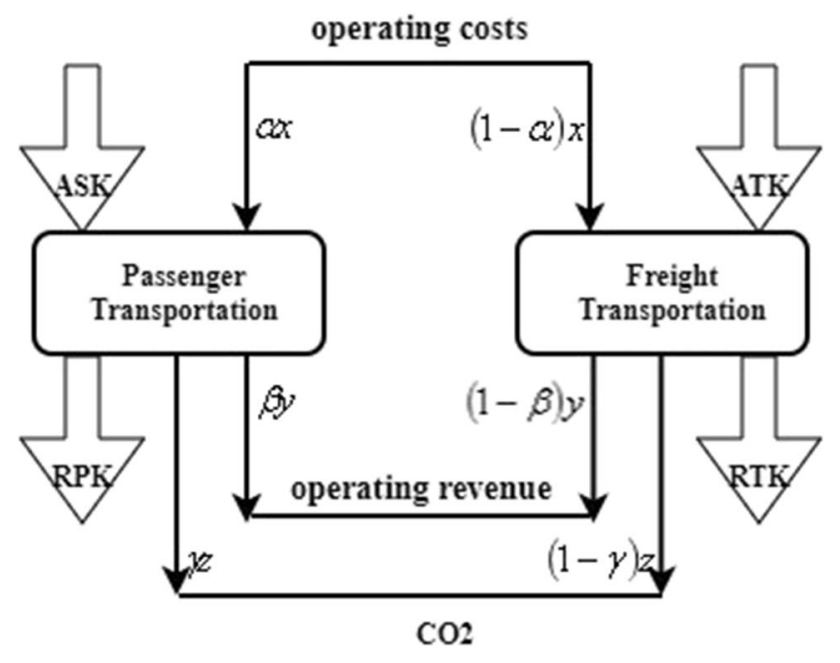

Fig. 1 A parallel system comprised of two transportation subsystems
Table 2 Quarterly input-output correlations

\begin{tabular}{lllll}
\hline & Operating revenue & $\mathrm{RPK}$ & $\mathrm{RTK}$ & $\mathrm{CO}_{2}$ \\
\hline Operating costs & $0.960 * * *$ & $0.816^{* * *}$ & $0.419 * * *$ & $0.606 * * *$ \\
ASK & $0.884 * * *$ & $0.992 * * *$ & $0.759 * * *$ & $0.769 * * *$ \\
ATK & $0.494 * * *$ & $0.758^{* * * *}$ & $0.989 * * *$ & $0.724 * * *$ \\
\hline
\end{tabular}

inputs, 1 intermediate output, and 1 final output to explore the resource sharing and payoff allocation. Omrani et al. (2021) selected 14 Iranian airlines, 4 input indicators, and 3 output indicators to evaluate the airline efficiency. So, the number of inputs and outputs in this paper is reasonable.

Considering that the lack of monthly operational data leads to the inaccuracy of the forecast, the quarterly data from the first quarter of 2018 to the last quarter of 2020 are chosen for the measurement. The data of ASK, ATK, RPK, RTK, operating cost, and operating revenue are mainly from the
Table 1 Descriptive statistics of the quarterly inputs and outputs during 2018-2021

\begin{tabular}{lllll}
\hline Variable & Mean & Std. dev & Min & Max \\
\hline The inputs & & & & \\
Operating costs (1,000,000 dollars) & $3,195.20$ & $2,509.27$ & 79.93 & $1,1934.74$ \\
Available seat kilometers (million) & $36,506.96$ & $26,868.61$ & 496.00 & $99,503.00$ \\
Available tonne kilometers (million) & $3,832.55$ & $2,932.33$ & 496.30 & $12,180.63$ \\
The desirable outputs & & & & \\
Operating revenue (1,000,000 dollars) & $3,209.95$ & $2,652.29$ & 62.14 & $12,298.49$ \\
Revenue passenger kilometers (million passenger-km) & $29,101.73$ & $22,863.97$ & 167.40 & $85,883.00$ \\
Revenue tonne kilometers (million tonne-km) & $2,589.42$ & $2,013.99$ & 281.90 & $8,631.73$ \\
The undesirable output & & & & \\
$\mathrm{CO}_{2}$ (1,000,000 tonnes) & 3.44 & 2.74 & 0.08 & 13.01 \\
\hline
\end{tabular}

airline's quarterly reports on its website. Some of the missing data come from monthly traffic data released by airlines. In addition, a few airlines published quarterly carbon dioxide emissions. Therefore, a rough calculation of $\mathrm{Co}_{2}$ emissions is done based on kerosene consumption for each quarter.

Descriptive statistics of quarterly input and output indicators are shown in Table 1 . There is a significant gap

Table 3 The regression analysis of quarterly input-output

\begin{tabular}{|c|c|c|c|c|c|c|c|c|c|c|c|c|}
\hline \multirow[t]{2}{*}{ Variables } & \multicolumn{3}{|c|}{ Operating revenue } & \multicolumn{3}{|l|}{ RPK } & \multicolumn{3}{|l|}{ RTK } & \multicolumn{3}{|l|}{$\mathrm{CO}_{2}$} \\
\hline & $\overline{R^{2}}$ & $p$ & $95 \% \mathrm{CI}$ & $\overline{R^{2}}$ & $p$ & $95 \% \mathrm{CI}$ & $\overline{R^{2}}$ & $p$ & $95 \% \mathrm{CI}$ & $\overline{R^{2}}$ & $p$ & $95 \% \mathrm{CI}$ \\
\hline Operating cost & 0.864 & 0.000 & $(0.489,0.687)$ & 0.783 & 0.000 & $(1.207,3.511)$ & 0.743 & 0.000 & $(0.165,0.270)$ & 0.433 & 0.000 & $(0.018,0.020)$ \\
\hline ASK & & 0.005 & $(0.043,0.062)$ & & 0.000 & $(0.700,0.803)$ & & & & & 0.000 & $(0.002,0.005)$ \\
\hline ATK & & 0.000 & $(0.103,0.173)$ & & & & & 0.000 & $(0.473,0.513)$ & & 0.000 & $(0.006,0.009)$ \\
\hline
\end{tabular}


between the indices of sample airlines, which indicates that each airline's operation mode and overall scale are different. The minimums typically appeared in the first and second quarters of 2020 when COVID-19 was very serious-compared the standard deviations of passenger and freight transportation specific inputs and outputs, the former $(26,868.61,22,863.97)$ and the latter $(2,932.33,2,013.99)$. It can be found that the latter is much smaller. The difference of minimum value between ASK and ATK is slight, but the maximum values differ by order of magnitude, as do RPK and RTK. This suggests that freight transportation is less affected by COVID-19.

The correlation coefficient and significance of quarterly input and output indicators are listed in Table 2. Most of the coefficients are positive and very high, also significant at the $1 \%$ level, which indicates that the selected inputs and outputs are related. For example, the correlation coefficient between operating cost and RTK is only 0.419 , and the correlation coefficient between ATK and operating revenue is 0.494 . However, the two groups are still significant at the level of $1 \%$. The reason may be that the airlines' freight services in the proportion are minimal, and the order of magnitude of freight volume differs significantly with other indexes, resulting in a relatively small correlation with inputs. We also did a regression analysis on the inputs and outputs as shown in Table 3 . The goodness of fit of the outputs are 0.864 (OR), 0.783 (RTK), 0.743 (RPK), and $0.433\left(\mathrm{CO}_{2}\right)$. The fitted values are not too high, indicating that the positive correlation between inputs and outputs is reasonable. $p$ value reflects the probability of occurrence of an event. The $p$ values in Table 3 are all less than 0.01, which means that the statistical difference is significant. The meaning of the last column of each output is that we used all samples to construct a confidence interval, $95 \%$ of which will contain the true values.

According to the economic impact analysis published by ICAO in April 2021, there are five shapes of economic recession and recovery:

- V-shaped: the economy smoothly returned to normal after a sharp recession.

- U-shaped: a long decline and weak economic recovery.

- L-shaped: economic activity is falling rapidly into a straight line and will not return to its former state.

- W-shaped: repeated fluctuations occur before full recovery showing a downward upward pattern.

- "Nike swoosh" shaped: the recovery speed is first fast and then slow.
The time series prediction method has been most mature in methods of prediction. Specific research can be seen in Li et al. (2018), Jia et al. (2020), and Ding et al. (2020). It acknowledges the continuity of the development of things, uses statistical analysis to predict development trends, and considers random volatility caused by accidental factors. Although the system's behavior is complex, the ordered data has an overall function. Therefore, it can be applied to study incomplete and accurate calculation, modeling, prediction, and data processing system. Referring to Cui et al. (2020), we construct the data matrix and vector after accumulation, then calculate the coefficients of the prediction model, and finally perform the staggering test and the correlation test. The above steps are realized by MATLAB software.

The forecast data can be obtained for the input-output indicators of 2021-2022. To prove the accuracy of the forecast results, a fitting analysis was performed on the inputs and outputs. Taking the upper bound of Aeroflot as an example, the fitting accuracy of the seven indicators are 0.564 (ATK), 0.677 (ASK), 0.563 (RTK), 0.541 (RSK), 0.4365 (OR), 0.6843 (OC), and $0.6948\left(\mathrm{CO}_{2}\right)$, respectively, which measure how well the predicted value fits the actual value. In general, if the degree of fitting is greater than 0.4 , the result is considered reasonable. Obviously, the value of Aeroflot is up to the standard. With the empirical progress, airlines have successively released operational data reports for the first two quarters of 2021. We also compared the actual the upper limits of the Aeroflot with the predicted values. The error ratios were $15 \%, 3 \%, 25 \%, 4 \%, 9 \%, 8 \%$, and $13 \%$, respectively. And the value less than $25 \%$ is within the normal range. The same is true for other airlines. After calculating the fitting accuracy and error rate of the upper bound of the 14 airlines, the overall average values are 0.613 and $16 \%$.

Descriptive statistics of them are listed in Table 4. The difference between the upper and lower input and output limits is significant, but several minimum and maximum values items are the same. Therefore, the road to recovery of airlines is still unstable in the future. Table 5 shows the correlation coefficients and significance between inputs and outputs in 2021-2022. All coefficients are positive and significant at the $1 \%$ level, ensuring the tight relationship between inputs and outputs. 
Table 4 Descriptive statistics of the quarterly inputs and outputs during 2021-2022

\begin{tabular}{|c|c|c|c|c|c|c|c|c|}
\hline \multirow[t]{2}{*}{ Variable } & \multicolumn{2}{|l|}{ Mean } & \multicolumn{2}{|l|}{ Std. dev } & \multicolumn{2}{|l|}{ Min } & \multicolumn{2}{|l|}{ Max } \\
\hline & Low & Up & Low & Up & Low & Up & Low & Up \\
\hline \multicolumn{9}{|l|}{ Inputs } \\
\hline Operating costs $(1,000,000$ dollars $)$ & 1984.01 & 2019.83 & 1401.73 & 1495.73 & 79.32 & 79.32 & 5379.86 & 5969.24 \\
\hline Available seat kilometers (million) & 18766.41 & 19427.58 & 14415.49 & 14426.04 & 839.73 & 1348.00 & 57232.80 & 57232.80 \\
\hline Available tonne kilometers (million) & 2728.72 & 2747.54 & 2054.96 & 2079.73 & 949.30 & 1049.04 & 8924.17 & 8924.17 \\
\hline \multicolumn{9}{|l|}{ Desirable outputs } \\
\hline Operating revenue $(1,000,000$ dollars $)$ & 1495.96 & 1544.40 & 990.71 & 1047.25 & 61.66 & 61.66 & 3981.01 & 4636.64 \\
\hline Revenue passenger kilometers (million passenger-km) & 12084.01 & 13384.51 & 9768.49 & 10246.13 & 224.00 & 224.00 & 42011.22 & 42011.22 \\
\hline Revenue tonne kilometers (million tonne-km) & 1759.40 & 1792.01 & 1137.62 & 1143.58 & 572.19 & 600.75 & 5491.91 & 5491.91 \\
\hline \multicolumn{9}{|l|}{ Undesirable outputs } \\
\hline $\mathrm{CO}_{2}(1,000,000$ tonnes $)$ & 1.68 & 1.77 & 1.43 & 1.49 & 0.02 & 0.08 & 4.99 & 4.99 \\
\hline
\end{tabular}

Table 5 Input-output correlations during 2021-2022

\begin{tabular}{|c|c|c|c|c|c|c|c|c|}
\hline & \multicolumn{2}{|c|}{ Operating revenue } & \multicolumn{2}{|l|}{ RPK } & \multicolumn{2}{|l|}{ PTK } & \multicolumn{2}{|l|}{$\mathrm{CO}_{2}$} \\
\hline & Low & $\mathrm{Up}$ & Low & Up & Low & Up & Low & Up \\
\hline Operating costs & $0.932 * * *$ & $0.971 * * *$ & $0.518 * * *$ & $0.641 * * *$ & $0.510 * * *$ & $0.534 * * *$ & $0.618^{* * *}$ & $0.615 * * *$ \\
\hline ASK & $0.721 * * *$ & $0.796 * * *$ & $0.943 * * *$ & $0.984 * * *$ & $0.858 * * *$ & $0.846^{* * *}$ & $0.738 * * *$ & $0.771 * * *$ \\
\hline ATK & $0.605 * * *$ & $0.650 * * *$ & $0.888 * * *$ & $0.872 * * *$ & $0.980 * * *$ & $0.984 * * *$ & $0.633 * * *$ & $0.662 * * *$ \\
\hline
\end{tabular}

to Li and Cui et al. (2018), the passenger and freight subsystems have equal weights $\left[\frac{1}{2}, \frac{1}{2}\right]$.

The detailed network EBM model is:
The weight of a parallel system significantly impacts efficiency, so it needs to be set in advance. For example, referred

$$
\begin{gathered}
\gamma^{*}=\min \left(\frac{1}{2} \times\left(\varphi_{1}+\varphi_{2}\right)-\frac{1}{2} \times\left(\varepsilon_{x 1} \times\left(\frac{w^{\alpha O C} s_{0}^{\alpha O C}}{\alpha O C}+\frac{w^{A T K} s_{0}^{A T K}}{\mathrm{ATK}}+\frac{w^{\gamma G H G} s_{0}^{\gamma G H G}}{\gamma G H G}\right)+\varepsilon_{x 2} \times\left(\frac{w^{(1-\alpha)} s_{o}^{(1-\alpha) O C}}{(1-\alpha) O C}+\frac{w^{A S K} s_{o}^{A S K}}{\mathrm{ASK}}+\frac{w^{(1-\gamma) G H G} s_{o}^{(1-\gamma) G H G}}{(1-\gamma) G H G}\right)\right)\right) \\
\text { s.t. } \varphi_{1} * A T K_{0}=\sum_{k}^{K} \lambda_{k} * A T K_{k}+s_{0}^{A T K} \\
\varphi_{1} * R T K_{0} \leq \sum_{k}^{K} \lambda_{k} * R T K_{k} \\
\varphi_{1} * \alpha * O C_{0}=\sum_{k}^{K} \lambda_{k} * \alpha * O C_{k}+s_{0}^{\alpha O C} \\
\varphi_{1} * \beta * O R_{0} \leq \sum_{k}^{K} \lambda_{k} * \beta * O R_{k} \\
\varphi_{1} * \gamma * G H G_{0} \leq \sum_{k}^{K} \lambda_{k} * \gamma * G H G_{k}+s_{0}^{\gamma G H G} \\
\sum_{k}^{K} \lambda_{k}=1 \\
\varphi_{2} * A S K_{0}=\sum_{k}^{K} \mu_{k} * A S K_{k}+s_{0}^{A S K} \\
\varphi_{2} * R P K_{0} \leq \sum_{k}^{K} \mu_{k} * R P K_{k} \\
\varphi_{2} *(1-\alpha) * O C_{0}=\sum_{k}^{K} \mu_{k} *(1-\alpha) * O C_{k}+s_{0}^{(1-\alpha) O C} \\
\varphi_{2} *(1-\beta) * O R_{0} \leq \sum_{k}^{K} \mu_{k} *(1-\beta) * O R_{k} \\
\varphi_{2} *(1-\gamma) * G H G_{0}=\sum_{k}^{K} \mu_{k} *(1-\gamma) * G H G_{k}+s_{0}^{(1-\gamma) G H G} \\
\sum_{k}^{K} \mu^{k}=1
\end{gathered}
$$


In the model, all variables are non-negative.

The variables are as follows:

$A T K_{k} \quad$ Available tonne kilometers of airline $k$;

$R T K_{k} \quad$ Revenue tonne kilometers of airline $k$;

$O C_{k} \quad$ Operating costs of airline $k$;
$O R_{k} \quad$ Operating revenue of airline $k$;

$G \mathrm{HG}_{k} \quad \mathrm{CO}_{2}$ of airline $k$;

$A S K_{k} \quad$ Available seat kilometers of airline $k$;

$R P K_{k} \quad$ Revenue passenger kilometers of airline $k$;

The interval efficiency value is:

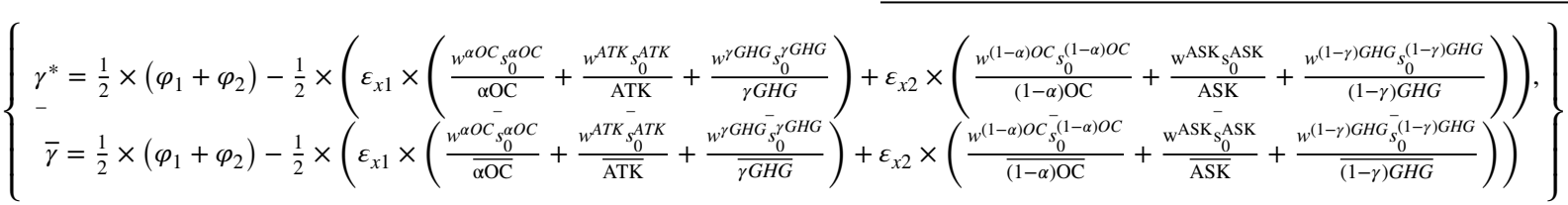

Table 6 The optimal $\alpha, \beta, \gamma$

\begin{tabular}{llll}
\hline Airlines & $\alpha$ & $\beta$ & $\gamma$ \\
\hline Aeroflot & 0.4373 & 0.5309 & 0.4479 \\
Air China & 0.4337 & 0.4728 & 0.6497 \\
All Nippon & 0.5301 & 0.5588 & 0.6423 \\
Cathay Pacific & 0.4604 & 0.5603 & 0.8118 \\
China Airlines & 0.4888 & 0.5494 & 0.7203 \\
China Eastern & 0.4938 & 0.4784 & 0.4264 \\
China Southern & 0.5024 & 0.4772 & 0.4068 \\
Eva Air & 0.4509 & 0.5204 & 0.5001 \\
Hainan & 0.5528 & 0.4701 & 0.6892 \\
Juneyao & 0.4909 & 0.4990 & 0.7465 \\
KLM Royal Dutch & 0.4282 & 0.5198 & 0.5053 \\
Lufthansa & 0.4857 & 0.4985 & 0.7468 \\
Singapore & 0.4874 & 0.6099 & 0.5823 \\
Spring & 0.5320 & 0.4677 & 0.5713 \\
\hline
\end{tabular}

Meanwhile, the efficiency value of the freight subsystem and passenger subsystem is:

$$
\begin{aligned}
& \varphi_{1}=\varphi_{1}-\varepsilon_{x 1} \times\left(\frac{w^{\alpha O C} s_{0}^{\alpha O C}}{\alpha \mathrm{OC}}+\frac{w^{A T K} s_{0}^{A T K}}{\mathrm{ATK}}+\frac{w^{\gamma G H G} s_{0}^{\gamma G H G}}{\gamma G H G}\right) \\
& \varphi_{2}=\varphi_{2}-\varepsilon_{x 2} \times\left(\frac{w^{(1-\alpha) O C} s_{0}^{(1-\alpha) O C}}{(1-\alpha) \mathrm{OC}}+\frac{\mathrm{w}^{\mathrm{ASK}} \mathrm{s}_{0}^{\mathrm{ASK}}}{\mathrm{ASK}}+\frac{w^{(1-\gamma) G H G} s_{0}^{(1-\gamma) G H G}}{(1-\gamma) G H G}\right)
\end{aligned}
$$

The 1stOpt software can help us get the optimal allocation ratio of 14 airlines and the optimal $\alpha, \beta, \gamma$, as shown in Table 6.

Then, the optimal solution of model (12) is the overall quarterly efficiency of 14 airlines during 2018-2020, as shown in Table 7 . Every quarter, the number of efficient airlines is $6,6,10,5,5,4,9,5,3,7,8$, and 5 . The efficiency value is higher in the third quarter because it is the peak travel season with passenger trips and freight volumes.

\begin{tabular}{|c|c|c|c|c|c|c|c|c|c|c|c|c|}
\hline \multirow[t]{2}{*}{ Airlines } & \multicolumn{4}{|l|}{2018} & \multicolumn{4}{|l|}{2019} & \multicolumn{4}{|l|}{2020} \\
\hline & Q1 & Q2 & Q3 & Q4 & Q1 & Q2 & Q3 & Q4 & Q1 & Q2 & Q3 & Q4 \\
\hline Aeroflot & 0.915 & 0.928 & 1.000 & 0.894 & 0.876 & 0.915 & 1.000 & 0.911 & 0.824 & 0.628 & 1.000 & 0.925 \\
\hline Air China & 0.984 & 1.000 & 1.000 & 1.000 & 0.970 & 1.000 & 1.000 & 0.963 & 0.817 & 1.000 & 1.000 & 0.983 \\
\hline All Nippon & 0.956 & 1.000 & 0.988 & 1.000 & 0.902 & 0.958 & 1.000 & 1.000 & 0.866 & 0.949 & 0.906 & 1.000 \\
\hline Cathay Pacific & 0.997 & 1.000 & 1.000 & 0.998 & 1.000 & 1.000 & 0.989 & 1.000 & 1.000 & 1.000 & 1.000 & 0.956 \\
\hline China Airlines & 1.000 & 0.963 & 0.991 & 0.963 & 1.000 & 0.985 & 1.000 & 0.985 & 1.000 & 1.000 & 1.000 & 0.940 \\
\hline China Eastern & 0.999 & 1.000 & 1.000 & 0.962 & 0.998 & 0.981 & 1.000 & 0.986 & 0.807 & 0.838 & 0.886 & 0.891 \\
\hline China Southern & 0.982 & 0.964 & 1.000 & 0.937 & 0.988 & 0.951 & 1.000 & 1.000 & 0.986 & 0.964 & 1.000 & 0.896 \\
\hline Eva Air & 1.000 & 0.943 & 0.977 & 0.941 & 1.000 & 1.000 & 0.930 & 0.873 & 1.000 & 1.000 & 0.989 & 1.000 \\
\hline Hainan & 1.000 & 1.000 & 1.00 & 0.977 & 1.000 & 1.000 & 1.000 & 0.949 & 0.925 & 0.898 & 0.964 & 1.000 \\
\hline Juneyao & 1.000 & 1.000 & 1.000 & 0.976 & 0.983 & 0.991 & 0.983 & 0.989 & 0.846 & 0.925 & 1.000 & 1.000 \\
\hline KLM Royal Dutch & 1.000 & 0.988 & 1.000 & 1.000 & 1.000 & 0.953 & 0.992 & 1.000 & 0.893 & 1.000 & 0.811 & 0.948 \\
\hline Lufthansa & 0.980 & 0.953 & 1.000 & 1.000 & 0.906 & 0.955 & 0.946 & 0.996 & 0.872 & 1.000 & 0.884 & 0.946 \\
\hline Singapore & 1.000 & 0.995 & 1.000 & 1.000 & 0.975 & 0.965 & 1.000 & 1.000 & 0.859 & 1.000 & 1.000 & 1.000 \\
\hline Spring & 0.964 & 0.973 & 0.972 & 0.930 & 0.995 & 0.989 & 1.000 & 0.947 & 0.824 & 0.907 & 1.000 & 0.977 \\
\hline Min & 0.915 & 0.928 & 0.972 & 0.894 & 0.876 & 0.915 & 0.930 & 0.873 & 0.807 & 0.628 & 0.811 & 0.891 \\
\hline Mean & 0.984 & 0.979 & 0.995 & 0.970 & 0.971 & 0.974 & 0.989 & 0.971 & 0.894 & 0.936 & 0.960 & 0.962 \\
\hline Std & 0.024 & 0.024 & 0.009 & 0.033 & 0.041 & 0.025 & 0.021 & 0.038 & 0.071 & 0.099 & 0.060 & 0.037 \\
\hline
\end{tabular}

Table 7 Overall quarterly environmental efficiency of the IEBM model during 2018-2020 
Table 8 Quarterly environmental efficiency of passenger subsystem with the IEBM model during 2018-2020

\begin{tabular}{|c|c|c|c|c|c|c|c|c|c|c|c|c|}
\hline \multirow[t]{2}{*}{ Airlines } & \multicolumn{4}{|l|}{2018} & \multicolumn{4}{|l|}{2019} & \multicolumn{4}{|l|}{2020} \\
\hline & Q1 & Q2 & Q3 & Q4 & Q1 & Q2 & Q3 & Q4 & Q1 & Q2 & Q3 & Q4 \\
\hline Aeroflot & 0.820 & 0.859 & 0.939 & 0.757 & 0.812 & 0.885 & 0.982 & 0.816 & 0.758 & 0.538 & 0.828 & 0.615 \\
\hline Air China & 0.955 & 0.968 & 1.000 & 0.975 & 0.964 & 1.000 & 1.000 & 0.954 & 0.798 & 1.000 & 1.000 & 0.972 \\
\hline All Nippon & 0.882 & 0.959 & 0.943 & 0.952 & 0.878 & 0.932 & 1.000 & 0.978 & 0.777 & 0.879 & 0.781 & 0.909 \\
\hline Cathay Pacific & 0.995 & 0.995 & 1.000 & 0.997 & 1.000 & 1.000 & 0.989 & 0.989 & 1.000 & 0.887 & 1.000 & 0.969 \\
\hline China Airlines & 1.000 & 0.854 & 0.850 & 0.839 & 0.901 & 0.904 & 0.921 & 0.914 & 1.000 & 1.000 & 0.898 & 0.871 \\
\hline China Eastern & 1.000 & 1.000 & 1.000 & 0.945 & 0.993 & 0.975 & 1.000 & 0.952 & 0.777 & 0.720 & 0.866 & 0.824 \\
\hline China Southern & 0.981 & 0.914 & 1.000 & 0.880 & 0.987 & 0.915 & 1.000 & 1.000 & 0.956 & 0.829 & 1.000 & 0.832 \\
\hline Eva Air & 0.965 & 0.881 & 0.916 & 0.878 & 1.000 & 1.000 & 0.898 & 0.811 & 0.982 & 0.997 & 0.952 & 0.805 \\
\hline Hainan & 1.000 & 0.986 & 1.000 & 0.933 & 1.000 & 1.000 & 1.000 & 0.913 & 0.879 & 0.809 & 0.945 & 1.000 \\
\hline Juneyao & 0.993 & 0.982 & 1.000 & 0.941 & 0.983 & 0.972 & 0.967 & 0.962 & 0.820 & 0.925 & 1.000 & 0.973 \\
\hline KLM Royal Dutch & 1.000 & 0.991 & 1.000 & 1.000 & 1.000 & 0.958 & 0.991 & 1.000 & 0.888 & 1.000 & 0.497 & 0.687 \\
\hline Lufthansa & 0.898 & 0.905 & 1.000 & 1.000 & 0.878 & 0.950 & 0.913 & 0.993 & 0.813 & 1.000 & 0.754 & 0.772 \\
\hline Singapore & 1.000 & 0.963 & 0.981 & 1.000 & 0.977 & 0.964 & 1.000 & 1.000 & 0.806 & 1.000 & 1.000 & 1.000 \\
\hline Spring & 0.952 & 0.950 & 0.966 & 0.891 & 0.986 & 0.966 & 1.000 & 0.911 & 0.804 & 0.868 & 1.000 & 0.948 \\
\hline Min & 0.820 & 0.854 & 0.850 & 0.757 & 0.812 & 0.885 & 0.898 & 0.811 & 0.758 & 0.538 & 0.497 & 0.615 \\
\hline Mean & 0.960 & 0.943 & 0.971 & 0.928 & 0.954 & 0.959 & 0.976 & 0.942 & 0.861 & 0.889 & 0.894 & 0.870 \\
\hline$S t d$ & 0.054 & 0.049 & 0.043 & 0.069 & 0.059 & 0.036 & 0.035 & 0.061 & 0.085 & 0.130 & 0.138 & 0.116 \\
\hline
\end{tabular}

Table 9 Quarterly environmental efficiency of freight subsystem with the IEBM model during 2018-2020

\begin{tabular}{|c|c|c|c|c|c|c|c|c|c|c|c|c|}
\hline \multirow[t]{2}{*}{ Airlines } & \multicolumn{4}{|l|}{2018} & \multicolumn{4}{|l|}{2019} & \multicolumn{4}{|l|}{2020} \\
\hline & Q1 & Q2 & Q3 & Q4 & Q1 & Q2 & Q3 & Q4 & Q1 & Q2 & Q3 & Q4 \\
\hline Aeroflot & 0.917 & 0.927 & 1.000 & 0.886 & 0.875 & 0.914 & 1.000 & 0.908 & 0.763 & 0.618 & 1.000 & 0.882 \\
\hline Air China & 0.945 & 1.000 & 0.975 & 1.000 & 0.901 & 1.000 & 1.000 & 0.939 & 0.804 & 1.000 & 1.000 & 0.987 \\
\hline All Nippon & 0.946 & 1.000 & 0.973 & 0.988 & 0.865 & 0.955 & 1.000 & 0.991 & 0.866 & 0.852 & 0.896 & 1.000 \\
\hline Cathay Pacific & 0.996 & 1.000 & 1.000 & 0.999 & 1.000 & 0.998 & 0.988 & 1.000 & 1.000 & 1.000 & 1.000 & 0.998 \\
\hline China Airlines & 0.769 & 0.879 & 0.916 & 0.883 & 0.953 & 0.917 & 0.932 & 0.881 & 1.000 & 0.917 & 0.901 & 0.910 \\
\hline China Eastern & 0.992 & 1.000 & 1.000 & 0.883 & 0.974 & 0.978 & 1.000 & 0.983 & 0.780 & 0.702 & 0.881 & 0.849 \\
\hline China Southern & 0.970 & 0.927 & 1.000 & 0.892 & 0.969 & 0.922 & 1.000 & 1.000 & 0.971 & 0.770 & 1.000 & 0.820 \\
\hline Eva Air & 0.987 & 0.922 & 0.955 & 0.922 & 1.000 & 1.000 & 0.908 & 0.842 & 0.942 & 0.905 & 0.885 & 1.000 \\
\hline Hainan & 0.996 & 1.000 & 1.000 & 0.968 & 1.000 & 1.000 & 0.990 & 0.887 & 0.912 & 0.857 & 0.930 & 1.000 \\
\hline Juneyao & 0.994 & 0.993 & 1.000 & 0.947 & 0.973 & 0.962 & 0.957 & 0.957 & 0.851 & 0.877 & 1.000 & 1.000 \\
\hline KLM Royal Dutch & 1.000 & 0.929 & 0.972 & 1.000 & 0.976 & 0.821 & 0.930 & 1.000 & 0.848 & 1.000 & 0.813 & 0.942 \\
\hline Lufthansa & 0.959 & 0.929 & 1.000 & 1.000 & 0.883 & 0.916 & 0.898 & 0.983 & 0.842 & 0.791 & 0.814 & 0.847 \\
\hline Singapore & 0.995 & 0.968 & 0.974 & 1.000 & 0.972 & 0.949 & 0.959 & 1.000 & 0.821 & 0.826 & 0.840 & 0.977 \\
\hline Spring & 0.947 & 0.951 & 0.965 & 0.896 & 0.980 & 0.971 & 1.000 & 0.918 & 0.822 & 0.902 & 1.000 & 0.970 \\
\hline Min & 0.769 & 0.879 & 0.916 & 0.883 & 0.865 & 0.821 & 0.898 & 0.842 & 0.763 & 0.618 & 0.813 & 0.820 \\
\hline Mean & 0.958 & 0.959 & 0.981 & 0.947 & 0.952 & 0.950 & 0.969 & 0.949 & 0.873 & 0.858 & 0.926 & 0.942 \\
\hline Std & 0.058 & 0.039 & 0.024 & 0.049 & 0.047 & 0.048 & 0.036 & 0.052 & 0.076 & 0.108 & 0.071 & 0.064 \\
\hline
\end{tabular}

Starting from the fourth quarter of 2019 , the quarterly efficiency of major airlines declined rapidly. The minimum values were all less than 0.900 , and the maximum average value was only 0.971 , much lower than before. The standard deviation fluctuation ranges of efficiency values also changed from $(0.009,0.041)$ to $(0.037,0.099)$. Because of the full outbreak of COVID-19 in the first quarter of 2020, the quarterly average efficiency value was only 0.894 that is the only one below 0.900 . Aeroflot is least efficient in Q2, 2020. According to the published second quarter report, the company completed a passenger turnover of 3,681 million passenger kilometers, $90.7 \%$ less than in 2019. It carried $1,731,000$ passengers, which fell $88.8 \%$ from a year ago. The net profit loss was as high as 453.90 million. Capacity cuts, 
Fig. 2 The average quarterly environmental efficiency of 14 airlines during 2018-2020

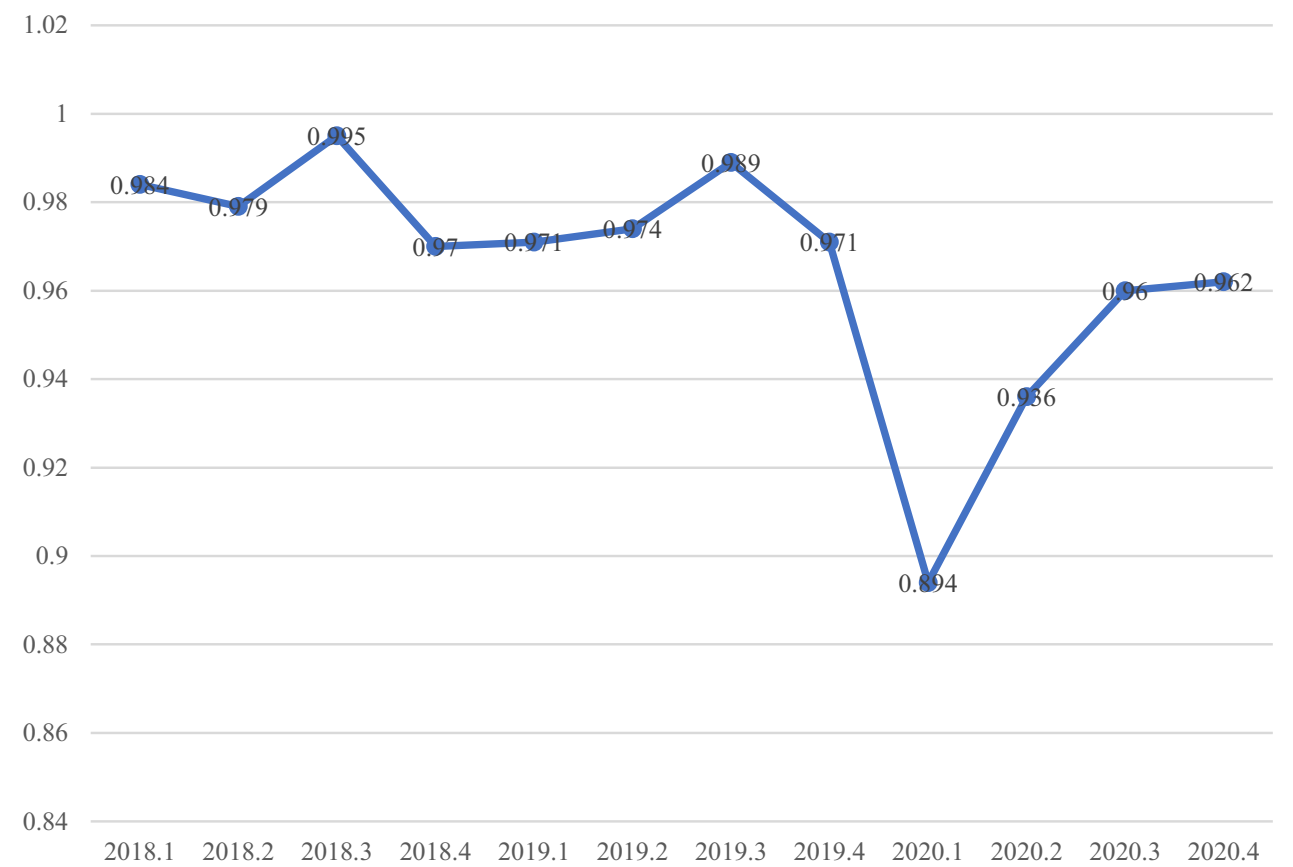

revenue decreases, and liquidity crises are specific manifestations of the epidemic's impact on airlines, ultimately leading to decreased efficiency. Cathay Pacific Airways performed well among the sample airlines, whose efficiency value had been 1.000 for four consecutive quarters. In 2020, Cathay Pacific Airways conducted several cost-cutting measures, such as aircraft deliveries delay, a hiring moratorium, and two rounds of special leave for staff. The airline also received about HK $\$ 2.689$ billion in government grants. The imbalance between available capacity and demand for medical supplies increased revenues. Cathay Pacific operated 5,648 full-cargo flights to boost power and refit four Boeing 777-300s to accommodate cargo in the cabin. Revenue from the freight subsystem in 2020 was HK $\$ 24.573$ billion, up $16.2 \%$ from 2019.

The quarterly efficiency is calculated to research further the efficiency change of the passenger and freight subsystems. There are shared resources between passenger transport and freight transport systems. The 1stOpt software is applied with the general global optimization algorithm to get the optimal allocation ratio. Then, we rerun the EBM model to get the results and list them in Table 8 and 9. Combined with the overall efficiency in Table 6 and the average efficiency in Fig. 2, the quarterly average efficiency values show a "Nike swoosh" $(\sqrt{ })$ type, namely the efficiencies slowly rising after the last drop, especially in the third and fourth quarters of 2020 . The overall average efficiencies were $0.971,0.894,0.936,0.960$, and 0.962 , while the efficiencies of passenger subsystem were $0.942,0.861,0.889,0.894$, and 0.870 and the efficiencies of freight subsystem were 0.949 ,
$0.873,0.858,0.926$, and 0.942 , respectively. This gives us the inspiration for predicting the data during 2021-2022.

Specific explanation of the change trend of efficiency is shown in Fig. 2. After the in-depth study of airline quarterly reports, we find that there is pressure from rising jet fuel prices for global airlines in 2018. The average global jet fuel price rose by approximately $31 \%$ year-on-year, and the profits of airlines had been affected to varying degrees. In addition, economic and geopolitical pressures led to an escalation of trade tensions, causing fluctuations

Table 10 The predicted and actual values of environmental efficiency in the first quarter of 2021

\begin{tabular}{lll}
\hline Airlines & Predicted & Actual \\
\hline Aeroflot & {$[1.000,1.000]$} & 0.990 \\
Air China & {$[0.878,0.880]$} & 0.878 \\
All Nippon & {$[1.000,1.000]$} & 0.803 \\
Cathay Pacific & {$[1.000,1.000]$} & 1.000 \\
China Airlines & {$[0.851,0.856]$} & 1.000 \\
China Eastern & {$[0.882,0.884]$} & 0.827 \\
China Southern & {$[1.000,1.000]$} & 0.877 \\
Eva Air & {$[1.000,1.000]$} & 1.000 \\
Hainan & {$[0.962,0.966]$} & 1.000 \\
Juneyao & {$[0.912,0.912]$} & 0.963 \\
KLM Royal Dutch & {$[1.000,1.000]$} & 0.896 \\
Lufthansa & {$[0.999,1.000]$} & 1.000 \\
Singapore & {$[1.000,1.000]$} & 0.896 \\
Spring & {$[0.896,0.899]$} & 1.000 \\
Mean & {$[0.956,0.957]$} & 0.938
\end{tabular}


Table 11 Overall quarterly environmental efficiency of the IEBM model during 2021-2022

\begin{tabular}{|c|c|c|c|c|c|c|c|}
\hline \multirow[t]{2}{*}{ Airlines } & \multicolumn{3}{|l|}{2021} & \multicolumn{4}{|l|}{2022} \\
\hline & Q2 & Q3 & Q4 & Q1 & $\mathrm{Q} 2$ & Q3 & Q4 \\
\hline Aeroflot & {$[0.797,0.900]$} & {$[0.790,0.902]$} & {$[0.896,0.944]$} & {$[0.934,1.000]$} & {$[0.998,1.000]$} & {$[0.990,1.000]$} & {$[1.000,1.000]$} \\
\hline Air China & {$[0.932,0.962]$} & {$[0.932,0.976]$} & {$[0.946,1.000]$} & {$[0.938,1.000]$} & {$[0.926,0.999]$} & {$[0.959,0.998]$} & {$[0.955,0.996]$} \\
\hline All Nippon & {$[0.912,0.922]$} & {$[0.911,0.979]$} & {$[0.909,1.000]$} & {$[0.909,0.916]$} & {$[0.917,1.000]$} & {$[0.921,0.991]$} & {$[0.924,0.983]$} \\
\hline Cathay Pacific & {$[0.993,1.000]$} & {$[0.990,0.994]$} & {$[0.992,1.000]$} & {$[0.906,1.000]$} & {$[0.907,1.000]$} & {$[0.914,0.996]$} & {$[0.911,0.995]$} \\
\hline China Airlines & {$[1.000,1.000]$} & {$[0.934,0.976]$} & {$[0.989,1.000]$} & {$[1.000,1.000]$} & {$[0.972,1.000]$} & {$[0.943,1.000]$} & {$[0.917,1.000]$} \\
\hline China Eastern & {$[0.855,0.877]$} & {$[0.839,0.868]$} & {$[0.822,0.861]$} & {$[0.854,0.859]$} & {$[0.866,0.870]$} & {$[0.874,0.874]$} & {$[0.881,0.882]$} \\
\hline China Southern & {$[0.929,0.938]$} & {$[0.930,0.941]$} & {$[0.931,0.946]$} & {$[0.913,0.932]$} & {$[0.916,0.943]$} & {$[0.919,0.920]$} & {$[0.923,0.923]$} \\
\hline Eva Air & {$[0.938,1.000]$} & {$[0.951,0.952]$} & {$[0.971,1.000]$} & {$[1.000,1.000]$} & {$[0.999,1.000]$} & {$[0.999,1.000]$} & {$[1.000,1.000]$} \\
\hline Hainan & {$[0.908,0.915]$} & {$[0.900,0.950]$} & {$[0.893,1.000]$} & {$[0.887,0.906]$} & {$[0.909,0.983]$} & {$[0.915,0.963]$} & {$[0.922,0.965]$} \\
\hline Juneyao & {$[0.925,0.940]$} & {$[0.924,0.949]$} & {$[0.922,1.000]$} & {$[0.927,0.939]$} & {$[0.944,0.947]$} & {$[0.935,0.943]$} & {$[0.940,0.948]$} \\
\hline KLM Royal Dutch & {$[0.948,0.960]$} & {$[0.971,0.972]$} & {$[0.984,1.000]$} & {$[0.954,1.000]$} & {$[0.938,0.996]$} & {$[0.923,0.984]$} & {$[0.908,0.974]$} \\
\hline Lufthansa & {$[0.924,0.937]$} & {$[0.915,0.942]$} & {$[0.948,1.000]$} & {$[0.957,0.982]$} & {$[0.970,0.987]$} & {$[0.951,1.000]$} & {$[0.938,0.965]$} \\
\hline Singapore & {$[0.985,1.000]$} & {$[0.990,1.000]$} & {$[0.994,1.000]$} & {$[0.816,1.000]$} & {$[0.830,0.970]$} & {$[0.848,0.966]$} & {$[0.865,0.961]$} \\
\hline Spring & {$[0.922,0.933]$} & {$[0.923,0.970]$} & {$[0.946,1.000]$} & {$[0.901,0.974]$} & {$[0.904,0.942]$} & {$[0.941,1.000]$} & {$[0.943,1.000]$} \\
\hline Mean & {$[0.926,0.949]$} & {$[0.921,0.955]$} & {$[0.939,0.982]$} & {$[0.921,0.965]$} & {$[0.928,0.974]$} & {$[0.931,0.974]$} & {$[0.931,0.971]$} \\
\hline
\end{tabular}

Table 12 Quarterly environmental efficiency of passenger subsystem with the IEBM model during 2021-2022

\begin{tabular}{|c|c|c|c|c|c|c|c|}
\hline \multirow[t]{2}{*}{ Airlines } & \multicolumn{3}{|l|}{2021} & \multicolumn{4}{|l|}{2022} \\
\hline & $\mathrm{Q} 2$ & Q3 & Q4 & $\mathrm{Q} 1$ & Q2 & Q3 & Q4 \\
\hline Aeroflot & {$[0.658,0.906]$} & {$[0.655,0.908]$} & {$[0.714,0.920]$} & {$[0.931,1.000]$} & {$[1.000,1.000]$} & {$[0.999,1.000]$} & {$[1.000,1.000]$} \\
\hline Air China & {$[0.958,0.983]$} & {$[0.978,0.988]$} & {$[0.994,1.000]$} & {$[1.000,1.000]$} & {$[0.986,1.000]$} & {$[0.987,0.998]$} & {$[0.982,0.996]$} \\
\hline All Nippon & {$[0.797,0.840]$} & {$[0.782,0.832]$} & {$[0.825,0.843]$} & {$[0.817,0.825]$} & {$[0.811,0.833]$} & {$[0.819,0.841]$} & {$[0.826,0.849]$} \\
\hline Cathay Pacific & {$[0.992,1.000]$} & {$[0.958,0.994]$} & {$[0.978,0.997]$} & {$[0.919,1.000]$} & {$[0.928,1.000]$} & {$[0.923,0.997]$} & {$[0.931,0.995]$} \\
\hline China Airlines & {$[0.897,1.000]$} & {$[0.913,0.926]$} & {$[0.907,1.000]$} & {$[0.830,0.910]$} & {$[0.796,0.998]$} & {$[0.766,1.000]$} & {$[0.740,1.000]$} \\
\hline China Eastern & {$[0.746,0.997]$} & {$[0.710,0.992]$} & {$[0.670,0.997]$} & {$[0.664,1.000]$} & {$[0.683,0.978]$} & {$[0.702,0.946]$} & {$[0.721,0.955]$} \\
\hline China Southern & {$[0.825,0.956]$} & {$[0.806,0.965]$} & {$[0.785,0.977]$} & {$[0.879,0.988]$} & {$[0.881,1.000]$} & {$[0.882,0.966]$} & {$[0.884,0.967]$} \\
\hline Eva Air & {$[0.953,1.000]$} & {$[0.763,0.954]$} & {$[0.736,0.979]$} & {$[0.930,0.985]$} & {$[0.916,0.919]$} & {$[0.903,0.912]$} & {$[0.904,0.909]$} \\
\hline Hainan & {$[0.911,0.929]$} & {$[0.936,0.948]$} & {$[0.954,1.000]$} & {$[0.898,0.996]$} & {$[0.898,1.000]$} & {$[0.904,0.944]$} & {$[0.910,0.945]$} \\
\hline Juneyao & {$[0.906,0.980]$} & {$[0.919,0.983]$} & {$[0.937,0.991]$} & {$[0.933,1.000]$} & {$[0.928,1.000]$} & {$[0.923,0.993]$} & {$[0.920,0.987]$} \\
\hline KLM Royal Dutch & {$[0.537,0.939]$} & {$[0.434,0.940]$} & {$[0.834,0.937]$} & {$[0.691,0.938]$} & {$[0.708,0.907]$} & {$[0.728,0.910]$} & {$[0.744,0.912]$} \\
\hline Lufthansa & {$[0.787,0.949]$} & {$[0.888,0.954]$} & {$[0.960,1.000]$} & {$[0.968,0.969]$} & {$[0.968,0.972]$} & {$[0.961,0.988]$} & {$[0.938,0.953]$} \\
\hline Singapore & {$[0.963,1.000]$} & {$[0.968,1.000]$} & {$[0.974,1.000]$} & {$[0.784,0.981]$} & {$[0.806,0.982]$} & {$[0.827,0.974]$} & {$[0.847,0.967]$} \\
\hline Spring & {$[0.909,0.988]$} & {$[0.952,0.998]$} & {$[0.979,0.998]$} & {$[0.878,1.000]$} & {$[0.885,0.991]$} & {$[0.989,1.000]$} & {$[0.989,1.000]$} \\
\hline Mean & {$[0.860,0.948]$} & {$[0.837,0.952]$} & {$[0.891,0.958]$} & {$[0.871,0.965]$} & {$[0.874,0.967]$} & {$[0.885,0.956]$} & {$[0.885,0.956]$} \\
\hline
\end{tabular}

in the operating efficiency of airlines. The third quarter is generally the peak tourist season, so the efficiency value of the third quarter of 2018 and 2019 was the highest, and then there was a decline. Compared to 2018, the quarterly efficiency values in 2019 are obviously lower. The most influential event that year was the grounding of the Boeing 737MAX aircraft, which was the longest duration in aviation history. Statistics from the IBA (aviation consulting agency) showed that 17 airlines worldwide have closed in 2019, most of which are European airlines. Starting in 2020, the main reason for the decline is the COVID-19.
Meanwhile, the warming climate and environmental pollution put forward requirements for airlines to achieve carbon neutrality. The efficiency value in the first quarter was the lowest, and then began to grow.

During the five quarters after the outbreak of COVID-19, the average efficiency of the freight subsystem was mostly higher than that of the passenger subsystem. The average efficiency values of the passenger and freight subsystems were 0.956 and 0.959 respectively during the seven quarters of 2018-2019 and then changed to 0.891 and 0.910 . This shows that the efficiency gap between passengers and freight 
Table 13 Quarterly environmental efficiency of freight subsystem with the IEBM model during 2021-2022

\begin{tabular}{|c|c|c|c|c|c|c|c|}
\hline \multirow[t]{2}{*}{ Airlines } & \multicolumn{3}{|l|}{2021} & \multicolumn{4}{|l|}{2022} \\
\hline & Q2 & Q3 & Q4 & Q1 & Q2 & Q3 & Q4 \\
\hline Aeroflot & {$[0.802,0.921]$} & {$[0.795,0.926]$} & {$[0.898,1.000]$} & {$[0.882,1.000]$} & {$[0.959,1.000]$} & {$[0.944,0.983]$} & {$[0.945,1.000]$} \\
\hline Air China & {$[0.937,0.960]$} & {$[0.955,0.966]$} & {$[1.000,1.000]$} & {$[0.922,1.000]$} & {$[0.924,0.935]$} & {$[0.926,0.947]$} & {$[0.951,0.929]$} \\
\hline All Nippon & {$[0.906,0.915]$} & {$[0.918,0.929]$} & {$[0.922,0.955]$} & {$[0.909,0.928]$} & {$[0.910,1.000]$} & {$[0.913,0.987]$} & {$[0.914,0.977]$} \\
\hline Cathay Pacific & {$[0.659,0.894]$} & {$[0.903,0.959]$} & {$[0.914,0.969]$} & {$[0.916,0.929]$} & {$[0.906,0.970]$} & {$[0.913,0.940]$} & {$[0.918,0.928]$} \\
\hline China Airlines & {$[0.883,0.897]$} & {$[0.908,0.943]$} & {$[0.936,1.000]$} & {$[0.956,1.000]$} & {$[0.922,1.000]$} & {$[0.891,0.991]$} & {$[0.878,0.986]$} \\
\hline China Eastern & {$[0.772,0.987]$} & {$[0.746,0.979]$} & {$[0.718,0.984]$} & {$[0.799,0.991]$} & {$[0.810,1.000]$} & {$[0.820,0.964]$} & {$[0.831,0.964]$} \\
\hline China Southern & {$[0.836,0.971]$} & {$[0.827,0.973]$} & {$[0.836,0.984]$} & {$[0.844,1.000]$} & {$[0.853,1.000]$} & {$[0.861,0.972]$} & {$[0.869,0.973]$} \\
\hline Eva Air & {$[0.884,0.967]$} & {$[0.925,0.972]$} & {$[0.989,1.000]$} & {$[1.000,1.000]$} & {$[0.999,1.000]$} & {$[0.993,0.999]$} & {$[1.000,1.000]$} \\
\hline Hainan & {$[0.887,0.934]$} & {$[0.932,0.932]$} & {$[0.956,1.000]$} & {$[0.855,0.982]$} & {$[0.859,0.980]$} & {$[0.867,0.958]$} & {$[0.874,0.942]$} \\
\hline Juneyao & {$[0.932,0.975]$} & {$[0.920,0.989]$} & {$[0.970,0.985]$} & {$[0.914,1.000]$} & {$[0.943,0.992]$} & {$[0.924,0.968]$} & {$[0.917,0.955]$} \\
\hline KLM Royal Dutch & {$[0.895,0.936]$} & {$[0.927,0.963]$} & {$[0.964,1.000]$} & {$[0.937,1.000]$} & {$[0.885,0.922]$} & {$[0.857,0.907]$} & {$[0.832,0.894]$} \\
\hline Lufthansa & {$[0.745,0.802]$} & {$[0.764,0.868]$} & {$[0.784,1.000]$} & {$[0.794,1.000]$} & {$[0.804,0.818]$} & {$[0.770,0.815]$} & {$[0.753,0.825]$} \\
\hline Singapore & {$[0.809,0.814]$} & {$[0.830,0.969]$} & {$[0.854,1.000]$} & {$[0.730,0.875]$} & {$[0.744,0.807]$} & {$[0.760,0.786]$} & {$[0.767,0.775]$} \\
\hline Spring & {$[0.929,0.995]$} & {$[0.989,0.962]$} & {$[0.994,1.000]$} & {$[0.894,1.000]$} & {$[0.905,0.986]$} & {$[0.981,1.000]$} & {$[0.988,1.000]$} \\
\hline Mean & {$[0.856,0.918]$} & {$[0.907,0.927]$} & {$[0.909,0.991]$} & {$[0.883,0.964]$} & {$[0.893,0.952]$} & {$[0.898,0.933]$} & {$[0.902,0.926]$} \\
\hline
\end{tabular}

Table 14 The quarterly average environmental efficiency and subsystem efficiency of airlines during 2021-2022

\begin{tabular}{llll}
\hline Airlines & Passenger & Freight & Overall \\
\hline Aeroflot & {$[0.838,0.958]$} & {$[0.920,0.962]$} & {$[0.926,0.968]$} \\
Air China & {$[0.965,0.990]$} & {$[0.932,0.970]$} & {$[0.933,0.976]$} \\
All Nippon & {$[0.817,0.832]$} & {$[0.921,0.960]$} & {$[0.925,0.974]$} \\
Cathay Pacific & {$[0.988,0.990]$} & {$[0.900,0.940]$} & {$[0.952,0.998]$} \\
China Airlines & {$[0.951,0.926]$} & {$[0.906,0.954]$} & {$[0.951,0.979]$} \\
China Eastern & {$[0.843,0.981]$} & {$[0.784,0.982]$} & {$[0.859,0.872]$} \\
China Southern & {$[0.889,0.977]$} & {$[0.851,0.984]$} & {$[0.933,0.943]$} \\
Eva Air & {$[0.901,0.948]$} & {$[0.968,0.984]$} & {$[0.982,0.994]$} \\
Hainan & {$[0.957,0.959]$} & {$[0.899,0.966]$} & {$[0.912,0.956]$} \\
Juneyao & {$[0.955,0.992]$} & {$[0.929,0.983]$} & {$[0.929,0.947]$} \\
KLM Royal Dutch & {$[0.773,0.909]$} & {$[0.940,0.925]$} & {$[0.953,0.986]$} \\
Lufthansa & {$[0.923,0.943]$} & {$[0.820,0.821]$} & {$[0.950,0.977]$} \\
Singapore & {$[0.965,0.926]$} & {$[0.831,0.859]$} & {$[0.916,0.987]$} \\
Spring & {$[0.961,0.994]$} & {$[0.946,0.992]$} & {$[0.922,0.965]$} \\
Average & {$[0.909,0.952]$} & {$[0.896,0.949]$} & {$[0.932,0.966]$} \\
\hline
\end{tabular}

has become significant. The minimums $(0.698,0.771)$ and standard deviations $(0.106,0.074)$ can also confirm it.

As the benchmark airline, Cathay Pacific Airways performed well in both passenger and cargo subsystems. The efficiency values of the five quarters were $(0.989,1.000$, $0.887,1.000,0.969)$ and $(1.000,1.000,1.000,1.000,0.998)$ respectively, which also proves that only when all subsystems are effective can the whole be effective in the DEA model. Singapore Airlines' subsystem efficiency values were $(1.000,0.806,1.000,1.000,1.000)$ and $(1.000,0.821,0.826$, $0.840,0.977)$. The contribution of the passenger system is more prominent. This shows that the capacity of most airlines' cargo systems increased during COVID-19, but not exclusively.

Airlines can learn from benchmark airlines and find room for improvement based on efficiency values so that they can recover quickly in the post-pandemic period. In particular, some subsystem efficiency of airlines is extreme, such as Aeroflot passenger efficiency (0.538) and freight efficiency (0.618) in Q2 2020 and KLM Royal Dutch passenger efficiency (0.497) in Q3 2020. An almost complete suspension of flights in April and May 2020 and the expenses on keeping the grounded fleet airworthy are the reason for Aeroflot. On the other hand, the leading cause of KLM Royal Dutch is the reduction in load factors for long-distance operations. Therefore, the slack values of the inputs and outputs are more specific.

Models (12)-(14) are applied to calculate the overall environmental efficiency value and subsystem environmental efficiency value of 14 airlines with the forecast interval data from 2021 to 2022 . Since 14 airlines successively released reports for the first quarter of 2021 during the empirical process, the operational data is collected to calculate the actual efficiency and compared it with the predicted value. As shown in Table 10, the expected efficiency value is not much different from the real value, which illustrates the feasibility of the prediction method.

The results are shown in Tables 11, 12, and 13. The 2-year average total and subsystem efficiencies of the 14 airlines are shown in Table 13. Except for China Eastern Airlines, the average efficiency values of other airlines are all higher than 0.900 . Combined with the average quarterly efficiencies in Table 8 , the efficiency values gradually increase, from 
[0.956, 0.957] in Q1 2021 to [0.931, 0.971] in Q4 2022. This is in line with "Nike swoosh" $(\sqrt{ })$ type of recovery curve.

Among them, the efficiency change of passenger subsystem is from $[0.840,0.913]$ to $[0.885,0.956]$, and the efficiency change of freight subsystem is from [0.922, 0.978] to $[0.902,0.926]$. The efficiency of the freight subsystem decreases, which is inevitable after the surge in 2020.

Only each subsystem is efficient; the overall efficiency can be efficient. However, the chance of that happening is meager. None of the airlines in Table 14 is completely efficient; that is, the upper efficiency and lower efficiency are both 1. From the point of a lower bound, airlines with high efficiency are Eva Air, Cathay Pacific, China Airlines, KLM Royal Dutch, and Lufthansa. Then, from the upper bound, Air China, Cathay Pacific, China Airlines, Eva Air, KLM Royal Dutch, Singapore, and Lufthansa are relatively efficient. The predicted upper efficiency value of Cathay Pacific is the largest (0.998), but its lower efficiency value (0.952) is less than Eva Air (0.982). After analyzing the importance of the subsystem, it can be found that the low efficiency of freight (0.900) leads to inefficiency. This shows that when Cathay Pacific Airways recovers in the future, the cargo system will have a broader space for revenue generation. Unlike Cathay Pacific, Eva Air's high efficiency is mainly due to the cargo subsystem [0.968, 0.984]. It will continue to play an important role in the future. China Eastern Airlines has the lowest efficiency value $[0.859,0.872]$ and its subsystems' efficiencies are $[0.843,0.981]$ and $[0.784,0.982]$. It means that it needs to take positive measures when facing a complex and severe external situation.

European airlines' recovery situation is better in regional terms, such as Aeroflot, KLM Royal Dutch, and Lufthansa. The average efficiency value on the low bound of the three airlines is $0.943,0.011$ higher than the overall average value. And the upper average efficiency is 0.977 , also higher than the overall average of 0.011 . The good development trend of Aeroflot Airlines lies in the formulation of targeted strategic decisions. The Aeroflot develops short-term plans (including the 2021 budget) and approves medium-term network and fleet plans. Meanwhile, it develops intergroup cooperation and prepares the code-share agreements. In addition to their own efforts, KLM Royal Dutch and Lufthansa also have the support of the European Union.

Chinese airlines (Air China, China Airlines, China Eastern, China Southern, Hainan, Juneyao, and Spring) do not perform well. Their average overall efficiency on the low bound is 0.920 , and the upper value is 0.948 , both lower than the overall average efficiency $[0.932,0.966]$. Observing the interval efficiency value of their subsystems, it can be found that the efficiency score of freight transportation is relatively low, indicating that Chinese airlines still have a lot of room for progress in freight service.

\section{Conclusions}

In the short term and medium term, the COVID-19 outbreak will significantly decline passenger and cargo volume. Therefore, it will profoundly impact the operation strategy, passenger and cargo source structure, and market competition mode in the medium term and long term. This paper proposes a novel interval EBM model to study the impact of COVID-19 on airline environmental efficiency and the future recovery trend of airlines. First, the airline operation is divided into two parallel subsystems-passenger and cargo, and select inputs and outputs: operating costs, available seat kilometers, available tonne kilometers, operating revenue, revenue passenger kilometers, revenue tonne kilometers, and carbon dioxide emission. Then 1stOpt software is used to determine the optimal allocation ratio of shared resources and apply time series prediction theory to predict the input-output interval data of 14 airlines. Finally, the overall and subsystem efficiencies are obtained by the IEBM model.

The main contributions of this paper are as follows. First, this is the first paper to discuss the impact of the COVID-19 on global airlines from the perspective of quarterly efficiency and interval data. This dramatically improves the accuracy of the evaluation. Second, the proposed interval EBM model overcomes the shortcomings of the traditional DEA models and combines the radial and non-radial models to evaluate the internal structure of the decision-making units. Third, we use strong disposability to deal with the undesirable output; the result is more reasonable.

This paper draws some interesting conclusions. First, the impact of the COVID-19 on airline passenger transportation is more significant than that on freight transportation. In the post-epidemic era, the efficiency of the freight subsystem will decline. Second, Cathay Pacific and EVA Air performed well and became the benchmark airlines, while China Eastern Airlines has the lowest efficiency value among the 14 airlines. Third, the airline's recovery curve is in a " $\sqrt{ }$ " shape, and operating conditions will gradually improve during 2021-2022. Fourth, European airlines are more efficient, and Chinese airlines still need to pay more attention to the cargo subsystem in the next few years.

The types of airlines (full-service carriers or low-cost carriers) should be considered in future research because different kinds of airlines have different operation strategies. Combined with the Malmquist production index, the efficiency differences between different regions can be explored. In addition to the passenger and freight subsystems, other departments can finally serve as the third possibility. Finally, our model does not consider intermediate output, which is also a point that can be discussed later. 
Author contribution Ye Li and Qiang Cui designed the study. Qiang Cui and Xingchun Huang performed the analysis and prepared the manuscript. Xingchun Huang compiled the original data. All authors participated in the writing of the manuscript.

Funding This research is funded by the National Natural Science Foundation of China (No. 71701088).

Data availability The datasets used and/or analyzed during the current study are available from the corresponding author on reasonable request.

\section{Declarations}

Ethics approval Not applicable.

Consent to participate We voluntarily agree to participate in this research study.

Consent to publish Not applicable.

Competing interests The authors declare no competing interests.

\section{References}

Adabavazeh N, Nikbakht M (2020) Organization's performance measurement model based on the critical success factors of the reverse supply chain in airline industry with a quality gap approach. J Ind Eng Manag Stud 7(1):177-190

Aida K, Cooper WW, Pastor JT, Sueyoshid T (1998) Evaluating water supply services in Japan with RAM: a range-adjusted measure of inefficiency. Omega 26(2):207-232

An Q, Meng F, Xiong B (2018) Interval cross efficiency for fully ranking decision making units using DEA/AHP approach. Ann Oper Res 271(2):297-317

An Q, Wen Y, Ding T, Li Y (2019) Resource sharing and payoff allocation in a three-stage system: integrating network DEA with the Shapley value method. Omega 85:16-25

Arana-Jiménez M, Sánchez-Gil MC, Younesi A, Lozano S (2021) Integer interval DEA: an axiomatic derivation of the technology and an additive, slacks-based model. Fuzzy Sets Syst 422:83-105

Azizi H, Wang YM (2013) Improved DEA models for measuring interval efficiencies of decision-making units. Measurement 46(3):1325-1332

Bae K, Gupta A, Mau R (2021) Comparative analysis of airline financial and operational performances: a fuzzy AHP and TOPSIS integrated approach. Decision Sci Lett 10(3):361-374

Barbot C, Costa A, Sochirca E (2008) Airlines performance in the new market context: a comparative productivity and efficiency analysis. J Air Transp Manag 14:270-274

Barros CP, Wanke P (2015) An analysis of African airlines efficiency with two-stage TOPSIS and neural networks. J Air Transp Manag 44-45:90-102

Bhadra D (2009) Race to the bottom or swimming upstream: performance analysis of US airlines. J Air Transp Manag 15:227-235

Budd L, Ison S, Adrienne N (2020) European airline response to the COVID-19 pandemic - contraction, consolidation and future considerations for airline business and management. Res Transp Bus Manag 37:100578
Cheng GQ, Wang L, Wang YM (2020) An extended three-stage DEA model with interval inputs and outputs. Int J Comp Intell Syst 14(1):43-53

Cooper WW, Park KS, Yu G (1999) IDEA and AR-IDEA: models for dealing with imprecise data in DEA. Manag Sci 45(4):597-607

Cui Q, Arjomandi A (2021) Airline energy efficiency measures based on an epsilon-based range-adjusted measure model. Energy 217:119354

Cui Q, Li Y (2018) CNG2020 strategy and airline efficiency: a network epsilon-based measure with managerial disposability. Int J Sustain Transp 12(5):313-323

Cui Q, Li Y, Wei YM (2018) Comparison analysis of airline energy efficiency under weak disposability and strong disposability using a virtual frontier slack-based measure model. Transp J 57(1):112-135

Cui Q, Lin JL, Jin ZY (2020) Evaluating airline efficiency under "Carbon Neutral Growth from 2020" strategy through a network interval slack-based measure. Energy 193:116734

Czerny AI, Fu X, Zheng L, Oum TH (2021) Post pandemic aviation market recovery: experience and lessons from China. J Air Transp Manag 90:101971

Davoudabadi R, Mousavi SM, Mohagheghi V (2021) A new decision model based on DEA and simulation to evaluate renewable energy projects under interval-valued intuitionistic fuzzy uncertainty. Renew Energy 164:1588-1601

Ding S, Xu N, Ye J, Zhou W, Zhang X (2020) Estimating Chinese energy-related $\mathrm{CO} 2$ emissions by employing a novel discrete grey prediction model. J Clean Prod 259:120793

Givoni M, Chen X (2017) Airline and railway disintegration in China: the case of Shanghai Hongqiao Integrated Transport Hub. Transp Lett 9(4):202-214

Greer MR (2008) Nothing focuses the mind on productivity quite like the fear of liquidation: changes in airline productivity in the united states, 2000-2004. Transp Res Part A:Policy Pract 42(2):414-426

Heydari C, Omrani H, Taghizadeh R (2020) A fully fuzzy network DEA-range adjusted measure model for evaluating airlines efficiency: a case of Iran. J Air Transp Manag 89:101923

Hong S, Zhang A (2010) An efficiency study of airlines and air cargo/ passenger divisions: a DEA approach. World Rev Intermodal Transp Res 3:137-149

ICAO, (2021) Effects of Novel Coronavirus (COVID-19) on Civil Aviation: Economic Impact Analysis. https://www.icao.int/susta inability/Pages/Economic-Impacts-of-COVID-19.aspx. Accessed 23 Nov 2021.

Jia ZQ, Zhou ZF, Zhang HJ, Li B, Zhang YX (2020) Forecast of coal consumption in Gansu Province based on Grey-Markov chain model. Energy 199:117444

Kuo MS (2011) A novel interval-valued fuzzy MCDM method for improving airlines' service quality in Chinese cross-strait airlines. Transp Res Part E: Logist Transp Rev 47(6):1177-1193

Lee YK, Park KS, Kim SH (2002) Identification of inefficiencies in an additive model based IDEA (imprecise data envelopment analysis). Comput Oper Res 29(12):1661-1676

Li Y, Cui Q (2018) Airline efficiency with optimal employee allocation: an input-shared network range adjusted measure. J Air Transp Manag 73:150-162

Li M, Wang W, De G, Ji X, Tan Z (2018) Forecasting carbon emissions related to energy consumption in Beijing-Tianjin-Hebei region based on grey prediction theory and extreme learning machine optimized by support vector machine algorithm. Energies 11(9): 2475

Merkert R, Hensher DA (2011) The impact of strategic management and fleet planning on airline efficiency-a random effects Tobit model based on DEA efficiency scores. Transp Res A 45(7):686-695 
Min H, Joo SJ (2016) A comparative performance analysis of airline strategic alliances using data envelopment analysis. J Air Transp Manag 52:99-110

Nižetić S (2020) Impact of coronavirus (COVID-19) pandemic on air transport mobility, energy, and environment: a case study. Int J Energy Res 44(13): 10953-10961

Omrani H, Valipour M, Emrouznejad A (2021) A novel best worst method robust data envelopment analysis: incorporating decision makers' preferences in an uncertain environment. Oper Res Perspect 8:100184

Ouellette P, Petit P, Tessier-Parent LP, Vigeant S (2010) Introducing regulation in the measurement of efficiency, with an application to the Canadian air carriers industry. Eur J Oper Res 200:216-226

Pacagnella Junior AC, Hollaender PS, Mazzanati GV (2020) Infrastructure and flight consolidation efficiency of public and private Brazilian international airports: a two-stage DEA and Malmquist index approach. J Adv Transp 2020:2464869

Pappachan J (2020) Airport service quality dimensions and its influence on airline passengers' satisfaction in India. J Business Manag Stud 5(1):10-18

Poordavoodi A, Goudarzi MRM, Javadi HHS, Rahmani AM, Izadikhah M (2020) Toward a more accurate web service selection using modified interval DEA models with undesirable outputs. Computer Modeling in Engineering \& Sciences 123(2): 525-570.

Ray SC, Mukherjee K (1996) Decomposition of the Fisher ideal index of productivity: a non-parametric dual analysis of US airlines data. Econ J 106(439):1659-1678

Siregar DD, Norsworthy JR, (2001). Pre- and post-deregulation financial performance and efficiency in US Airlines. Change Management and the New Industrial Revolution, 200. IEMC '01 Proceedings, pp. 421-429.

Suau-Sanchez P, Voltes-Dorta A, Cugueró-Escofet N (2020) An early assessment of the impact of COVID-19 on air transport: just another crisis or the end of aviation as we know it? J Transp Geogr 86:102749

Sun JW (2005) The decrease of CO2emission intensity is decarbonization at national and global levels. Energy Policy 33:975-978

Sun XM, Zhang H, Wang G (2016) Research on regional carbon emission efficiency based on super-efficiency SBM model_taking 17 prefecture-level cities in Shandong Province as examples. Ecol Econ 32(05):68-73
Tavana M, Mirzagoltabar H, Mirhedayatian SM, Saen RF (2013) A new network epsilon-based DEA model for supply chain performance evaluation. Comput Ind Eng 66(2):501-513

Tavassoli M, Fathi A, Farzipoor Saen R (2021) Developing a new super-efficiency DEA model in the presence of both zero data and stochastic data: a case study in the Iranian airline industry. Benchmarking: An International Journal 28(1):42-65

Tol RSJ, Pacala SW, Socolow RH (2009) Understanding long-term energy use and carbon emissions in the USA. J Policy Model 31:425-445

Tone K (2001) A slacks-based measure of efficiency in data envelopment analysis. Eur J Oper Res 130(3):498-509

Tone K, Tsutsui M (2010) An epsilon-based measure of efficiency in DEA--a third pole of technical efficiency. Eur J Oper Res 207(3):1554-1563

Wang YM, Greatbanks R, Yang JB (2005) Interval efficiency assessment using data envelopment analysis. Fuzzy Sets Syst 153(3):347-370

Wang WK, Lu WM, Tsai CJ (2011) The relationship between airline performance and corporate governance amongst US Listed companies. J Air Transp Manag 17(2):148-152

Wang CN, Nguyen NAT, Fu HP, Hsu HP, Dang TT (2021) Efficiency assessment of seaport terminal operators using DEA Malmquist and epsilon-based measure models. Axioms 10(2):48

Wu YY, He XJ (2006) Evaluation of Beijing's sustainable development ability based on DEA method. Beijing industry university, Beijing

Wu WY, Liao YK (2014) A balanced scorecard envelopment approach to assess airlines' performance. Ind Manag Data Syst 114(1):123-143(21)

Wu P, Wang Y, Chiu YH, Li Y, Lin TY (2019) Production efficiency and geographical location of Chinese coal enterprises-undesirable EBM DEA. Res Policy 64:101527

Xu X, Cui Q (2017) Evaluating airline energy efficiency: an integrated approach with network epsilon-based measure and network slacks-based measure. Energy 122:274-286

Zhou X, Wang Y, Chai J, Wang L, Wang S, Lev B (2019) Sustainable supply chain evaluation: a dynamic double frontier network DEA model with interval type-2 fuzzy data. Inf Sci 504:394-421

Publisher's note Springer Nature remains neutral with regard to jurisdictional claims in published maps and institutional affiliations. 